\title{
O DEVIDO PROCESSO LEGAL DE INTERNAÇÃO PSIQUIÁTRICA INVOLUNTÁRIA NA ORDEM JURÍDICA CONSTITUCIONAL BRASILEIRA
}

\author{
THE DUE PROCESS OF LAW FOR INVOLUNTARY PSYCHIATRIC \\ INTERNMENT IN BRAZILIAN CONSTITUTIONAL LAW
}

Gustavo Henrique de Aguiar Pinheiro ${ }^{(*)}$

\section{RESUMO}

A Constituição Federal de 1988 prevê que "ninguém será privado da liberdade ou de seus bens sem o devido processo legal" (Art. $5^{\circ}$, LIV). Essa cláusula derivada do direito inglês - due process of law - garante a todos um procedimento legal previamente estabelecido e um julgamento justo para a privação do direito fundamental à liberdade do paciente psiquiátrico. A internação psiquiátrica involuntária, além de seu aspecto médico, possui natureza de restrição ao direito de liberdade, sendo por isso exigido um devido processo legal. A natureza jurídico-constitucional da internação psiquiátrica involuntária e a sua constitucionalidade, embora não possa derivar de texto expresso da Constituição, advém do chamado "direitos dos outros", que autoriza a restrição de direitos fundamentais em confronto com outros direitos ou valores constitucionais. No Brasil, há uma previsão específica para o devido processo legal de internação psiquiátrica involuntária dada pela Lei $n^{\circ} 10.216 / 2001$, que dispõe sobre a proteção e os direitos das pessoas portadoras de transtornos mentais e redireciona o modelo assistencial em saúde mental. Entretanto, o princípio do amplo acesso ao poder judiciário (Art. $5^{\circ}, \mathrm{XXXV}$ ), a referida cláusula constitucional, autoriza o intérprete, principalmente o juiz, a maior concretização dos direitos fundamentais da pessoa portadora de transtorno mental. $O$ devido processo de internação psiquiátrica involuntária é matéria amplamente examinada do direito comparado, cujas diretrizes, diante das características

(*) Mestre em Direito Constitucional, Universidade Federal do Ceará (UFC); Especialista em Direito Processual Civil, Universidade de Fortaleza (UNIFOR); Especialista em Saúde Mental, Universidade Estadual do Ceará (UECE). Assessor Jurídico da Vice-Presidência do Tribunal de Justiça do Ceará. Coordenador Geral da ONG Escola Popular de Formação em Direito, Psicologia, Sociologia e Política. Fortaleza/CE - Brasil. E-mail: <gustavohap@uol.com.br>. Texto recebido em 21.05.10. Aprovado em 10.09.10 
do constitucionalismo contemporâneo, podem ser perfeitamente aplicadas ao Brasil. Estando a internação psiquiátrica involuntária, no caso concreto, em desobediência ao devido processo legal e às condições de salubridade previstas na lei da reforma psiquiátrica, a ação constitucional do habeas corpus pode e deve ser utilizada para assegurar o direito fundamental à liberdade da pessoa portadora de transtorno mental, até mesmo em face de ato de particular (diretores de clínicas ou hospitais), como autorizam a doutrina e a jurisprudência brasileira.

\section{Palavras-chave:}

Internação Involuntária; Processo Legal; Saúde Mental.

\section{ABSTRACT}

Brazilian Federal Constitution of 1988 stipulates that "no one shall be deprived of his freedom or possessions without the corresponding legal process" (Art $5^{\circ}$, LIV). This clause derives from English law - due process of law - and grants a previously established legal process for all and a fair trial in order to deprive the psychiatric patient of the fundamental right to freedom. Involuntary psychiatric internment, beyond its medical nature, implies a restriction to freedom rights, thus making a legal process necessary. The legal-constitutional nature of psychiatric internment and its constitutionality, although it does not derive from the expressed text of the Constitution, comes from the so-called "third-party rights" which authorize a restriction to fundamental rights when confronted to other rights or constitutional values. There is a specific provision for due legal processes for involuntary psychiatric internement in Brazil, as stipulated by Law n. 10.216/2001, which includes dispositions about protection of rights for the mentally handicapped and redefines the mental health assistance model. However, the principle of ample access to legal powers (Art. $5^{\circ}, \mathrm{XXXV}$ ) for the referred constitutional clause entitles the interpreter, mainly the jury, to a higher level of decision power with regards to the basic rights of mental health patients. The corresponding involuntary psychiatric internment process is a widely examined subject in comparative law, which offers guidelines that can be perfectly applied to the characteristics of contemporary constitutionalism in Brazil. Therefore, considering that involuntary psychiatric internment is in disagreement with due legal processes and health conditions foreseen in the psychiatric reform law, a constitutional habeas corpus petition can and should be considered to grant the fundamental right to freedom for the mentally handicapped patient, even in the case of private acts (such as clinic or hospital directors) as authorized by the Brazilian doctrine and jurisprudence.

\section{Keywords:}

Involuntary Internation; Legal Process; Mental Health. 


\section{INTRODUÇÃO}

A Constituição Federal de 1988 é o maior depositório de possibilidades em saúde mental. Conquanto essa assertiva seja ainda ignorada pela maioria dos juristas e profissionais de saúde mental, na Carta Magna estão presentes as potencialidades dos direitos fundamentais da pessoa portadora de transtorno mental, suas garantias e valores, à espera de concretização, sobretudo judicial, uma vez que a dignidade da pessoa humana é um valor a ser aplicado cotidianamente.

Nesse contexto, um estudo sobre a natureza jurídica da internação psiquiátrica involuntária, como fenômeno jurídico, e não apenas médico, é uma necessidade que poderá orientar essa prática médica, aproximando-a e integrando-a às diretrizes constitucionais, únicas possíveis de realizar plenamente o Estado Democrático de Direito e a dignidade da pessoa portadora de transtorno mental.

A internação psiquiátrica involuntária continua sendo um dos temas mais polêmicos em saúde mental, pois, medida extrema, vai de encontro à autonomia do portador de transtorno mental, princípio bioético que sustenta a transformação daquele de objeto em sujeito e se forja no ambiente superior das normas fundantes do novo modelo de assistência psiquiátrica brasileiro.

A condição de sujeito da pessoa portadora de transtorno mental implica direitos e garantias fundamentais na ordem jurídica constitucional.

Loucura, na contemporaneidade constitucional, é somente o não direito. $\mathrm{A}$ experiência do sofrimento psíquico, algo eminentemente humano, não atinge os direitos fundamentais daqueles que a vivenciam, sendo política e juridicamente inaceitável qualquer ideia que insista na mutilação das capacidades constitucionais (e não somente civis) desses indivíduos.

O devido processo legal é evolução histórica da sabedoria e do sofrimento da humanidade, que a linguagem jurídica expressa e toda a população precisa conhecer.

Evolução da evolução, corolário lógico das conquistas da dignidade humana, o devido processo legal de internação psiquiátrica é garantia inalienável de toda a pessoa que vivencia o sofrimento mental e, eventualmente, necessita sofrer também limitação em seu direito fundamental à liberdade.

\section{O DEVIDO PROCESSO LEGAL}

A expressão "devido processo legal" deriva do direito inglês due process of law e quer indicar a existência de um procedimento legalmente previsto para garantir direitos fundamentais dos cidadãos. Essa cláusula constitucional 
processual garante aos litigantes um processo justo ou, no caso em exame, uma internação psiquiátrica involuntária "justa".

A Constituição Federal determina expressamente que "ninguém será privado da liberdade ou de seus bens sem o devido processo legal" (Art. $5^{\circ}$, LIV).

Rui Portanova afirma que:

o devido processo legal é uma garantia do cidadão. Garantia constitucionalmente prevista que assegura tanto o exercício do direito de acesso ao Poder Judiciário como o desenvolvimento processual de acordo com normas previamente estabelecidas. Assim, pelo princípio do devido processo legal, a Constituição garante a todos os cidadãos que a solução de seus conflitos obedecerá aos mecanismos jurídicos de acesso e desenvolvimento do processo, conforme previamente estabelecido em leis ${ }^{1}$.

Temos, portanto, que o paciente psiquiátrico tem o direito constitucional de um devido processo legal de internação involuntária (sem o consentimento), ou compulsória (quando ordenado por juiz), que deverá obedecer a prévios padrões normativos, uma vez que se trata de evidente restrição ao direito fundamental à liberdade, e não apenas de "ato médico".

Possuem os direitos fundamentais das pessoas portadoras de transtornos mentais eficácia imediata, vinculando inclusive os particulares, como médicos, clínicas e hospitais, que estão constitucionalmente obrigados a seguir o devido processo legal para internação involuntária, pois é certo que quando da referida restrição a direito fundamental, além da dimensão individual, está em questão a dimensão social da dignidade da pessoa humana².

O Supremo Tribunal Federal reconhece expressamente que

as violações a direitos fundamentais não ocorrem somente no âmbito das relações entre o cidadão e o Estado, mas igualmente nas relações travadas entre pessoas físicas e jurídicas de direito privado. Assim, os direitos fundamentais assegurados pela Constituição vinculam diretamente não apenas os poderes públicos, estando direcionados também à proteção dos particulares em face dos poderes privados ${ }^{3}$.

Dessa forma, a cláusula constitucional do devido processo legal à internação psiquiátrica involuntária, ou compulsória, possui eficácia imediata contra o poder público e também em face dos particulares, que terão - ambos - de observar procedimento próprio para efetivar internações involuntárias e compulsórias, sob pena de tornar aludidos procedimentos inconstitucionais e flagrantemente nulos, a justificar as medidas materiais e processuais adequadas, tais como o habeas corpus.

(1) PORTANOVA, Rui. Princípio do processo civil. 4ª ed. Porto Alegre: Livraria do Advogado, 2001. p. 145.

(2) STEINMETZ, Wilson. A vinculação dos particulares a direitos fundamentais. São Paulo: Malheiros, 2004. p. 227.

(3) Supremo Tribunal Federal, Recurso extraordinário n²01819/RJ, Segunda Turma, Relator para acórdão Ministro Gilmar Mendes, Diário da Justiça de 27 de outubro de 2006. 


\section{A NATUREZA E A CONSTITUCIONALIDADE DA INTERNAÇÃO PSIQUIÁTRICA INVOLUNTÁRIA}

A natureza da internação psiquiátrica involuntária, embora não se possa cogitar de aspectos penais, é claramente de "restrição ao direito de liberdade", representando espécie de limitação civil ou administrativa a direito fundamental de defesa contra intervenção indevida do Estado (e/ou de particulares) e contra medidas legais restritivas dos direitos de liberdade.

Pondera o conceituado jurista português José Carlos Vieira de Andrade que, em se tratando de internação sem o consentimento do paciente,

de facto, estamos perante uma situação de restrição de direitos fundamentais: não haverá dúvidas de que, por um lado, o internamento compulsivo constitui uma privação de liberdade contra a vontade do interessado, e de que, por outro lado, o indivíduo portador de anomalia psíquica é uma pessoa física, titular de direitos fundamentais ${ }^{4}$.

\section{Como esclarece Paulo Bonavides,}

os direitos da primeira geração ou direitos de liberdade têm por titular o indivíduo, são oponíveis ao Estado, traduzem-se como faculdade ou atributos da pessoa e ostentam uma subjetividade que é seu traço mais característico; enfim, são direitos de resistência ou de oposição perante o Estado ${ }^{5}$.

A sempre admirável expressão Bonavideana, em registro acerca da obra de Carl Schmitt, faz consignar a opinião do jurista alemão, para quem os direitos de liberdade somente podem ser relativizados excepcionalmente, "segundo o critério da lei" ou "dentro dos limites legais"6.

Gilmar Ferreira Mendes confirma que "os direitos individuais enquanto [sic] direitos de hierarquia constitucional somente podem ser limitados por expressa disposição constitucional (restrição imediata) ou mediante lei ordinária promulgada com fundamento imediato na própria Constituição (restrição mediata)"”.

Assim, a limitação ao direito fundamental à liberdade de ir e vir imposta pela internação psiquiátrica involuntária somente poderia encontrar respaldo constitucional se fosse expressamente prevista no texto da Carta Magna ou se estivesse fundada em restrições legais, entendendo estas como aquelas limitações que o legislador impõe a determinados direitos individuais, respaldado em expressa autorização constitucional.

(4) ANDRADE, José Carlos Vieira de. O internamento compulsivo de portadores de anomalia psíquica na perspectiva dos direito fundamentais. In: CARVALHO, Álvaro de et al. (Orgs.). A lei de saúde mental e o internamento compulsivo, Coimbra: Coimbra Editora, 2000. p. 78.

(5) BONAVIDES, Paulo. Curso de direito constitucional. 13 ed, São Paulo: Malheiros, 2003. p. $563 / 564$.

(6) Id. Ibid., p. 561-562.

(7) MENDES, Gilmar Ferreira. Os direitos individuais e suas limitações: breves reflexões. In: MENDES, Gilmar Ferreira. Hermenêutica constitucional e direitos fundamentais. Brasília: Brasília Jurídica, 2002. p. 227. 
Noticia José Carlos Vieira de Andrade ${ }^{8}$ que a Constituição Portuguesa até o ano de 1997 - época da revisão constitucional - não previa expressamente a hipótese de internamento de portadores de anomalia psíquica no rol taxativo de casos autorizadores de privação da liberdade, o que certamente indica a atenção do legislador constituinte reformador português à tese de que tal espécie restritiva somente é admissível nos termos antes expostos.

Tanto é assim que o jurista luso entende constitucional o internamento compulsivo em seu país, uma vez agora excepcionado, pelo tempo e nas condições que a lei determinar, como forma de restrição de liberdade prevista na própria Constituição (Art. 273, "h"), desde que efetuado em estabelecimento terapêutico adequado, decretado ou confirmado por autoridade judicial competente.

A esse ponto, convém examinar se a Constituição Federal Brasileira autorizou diretamente a privação de liberdade do portador de transtorno mental nos casos de internação psiquiátrica involuntária ou se remeteu à lei ordinária tal possibilidade, únicas hipóteses em que a referida modalidade de intervenção ao direito fundamental à liberdade seriam admissíveis.

Na verdade, a Constituição brasileira não tratou da limitação à liberdade produzida pelo internamento psiquiátrico involuntário.

Com efeito, a Carta Magna de 1988, que tem como regra geral o respeito ao direito à liberdade, define hipóteses excepcionais de privação de liberdade, abrangendo prisões penais, processuais, civis e disciplinares, sem, no entanto, fazer nenhuma referência à internação psiquiátrica involuntária, até mesmo porque essa modalidade de restrição da liberdade não se realiza por motivos penais ou processuais penais, inadimplemento de obrigação alimentar ou infidelidade depositária ou, muito menos, por razões administrativas ou disciplinares, não podendo ser tecnicamente enquadrada como modalidade de "prisão"?.

Coube, em brevíssimas disposições, à Lei Federal n 10.216 de 6 de abril de 2001, que dispõe sobre a proteção e os direitos das pessoas portadoras de transtornos mentais e redireciona o modelo assistencial em saúde mental, a instituição e a regulamentação da internação psiquiátrica involuntária.

Entretanto, por tudo o que se afirmou sobre possibilidades excepcionais de restrições a direitos fundamentais, fácil é observar que a restrição à liberdade autorizada pela Lei Federal $n^{\circ} 10.216$ está em dissonância com os parâmetros constitucionais, pois, além de não existir autorização direta da Carta Magna para a mencionada limitação de direitos, a mencionada lei ordinária autoriza a imposição

(8) ANDRADE, José Carlos Vieira de. op. cit., p. 81-82

(9) O Tribunal Europeu dos Direitos do Homem, porém, em um louvável esforço de interpretação integradora, tem estendido as garantias típicas dos "presos" aos doentes mentais fora de um contexto penal. A notícia é de Irineu Cabral Barreto, juiz da referida Corte, no seu prestigiado $A$ Convenção Européia dos Direitos do Homem Anotada, $2^{a}$ ed, Coimbra: Coimbra Editora, 1999. 
da restrição ao portador de transtorno mental sem que a Constituição Ihe tenha dado autorização expressa.

Por tudo isso, existem indicações aparentes acerca da ausência de normas válidas no direito brasileiro que autorizem expressa e especificamente a espécie involuntária de internação psiquiátrica.

Perceba-se que não se está afirmando a inconstitucionalidade da modalidade interventiva, haja vista ser ela constitucionalmente admitida por outros fundamentos.

Com efeito, "a doutrina do direito comparado parece unânime de que nem tudo o que se encontra protegido, em tese, pelo âmbito de proteção dos direitos fundamentais sem reserva legal expressa (...) colhe efetiva proteção dos direitos fundamentais"10.

Gilmar Ferreira Mendes novamente esclarece:

A Corte Constitucional alemã, chamada a se pronunciar sobre o tema no caso relacionado com a recusa à prestação de serviço militar, assim se manifestou:

"Apenas a colisão entre direitos de terceiros e outros valores jurídicos com hierarquia constitucional podem excepcionalmente, em consideração à unidade da Constituição e à sua ordem de valores, legitimar o estabelecimento de restrições a direitos não submetidos a uma expressa reserva legal".

A possibilidade de uma colisão legitimaria, assim, o estabelecimento de restrição a um direito não submetido a uma reserva legal expressa.

A propósito, anota Gavara de Cara que, nesses casos, o legislador pode justificar sua intervenção com fundamentos nos direitos de terceiros ou em outros princípios de hierarquia constitucional.

Entre nós, a atividade legislativa, nessas hipóteses, estaria facilitada pela cláusula de reserva legal subsidiária contida no Art. $5^{\circ}$, II, da Constituição ${ }^{11}$.

Embora a Lei Federal $n^{\circ} 10.216 / 2001$ não tenha autorização constitucional expressa para restringir o direito à liberdade dos pacientes psiquiátricos involuntários, é notório que a internação sem consentimento pode existir plenamente diante, dentre outros fatores posteriormente examinados, de possibilidade de danos para si ou para terceiros, ou seja, violação a direitos fundamentais próprios (tentativa de suicídio, por exemplo) ou de outrem (vida, integridade física, propriedade etc.).

O jurista português Jorge Reis Novais menciona a doutrina do "direito dos outros" como aquela de limites imanentes mais divulgada e mais aceita como fonte de limitações ou restrições não expressamente autorizada aos direitos fundamentais.

(10) MENDES, op. cit., p. 240.

(11) MENDES, op. cit., p. 240. 
Para o autor "ela surge por força do reconhecimento imperativo de que, em Estado de Direito, o princípio da igual dignidade de todos impõe à liberdade de cada um as limitações decorrentes do reconhecimento recíproco da igual liberdade dos outros"12.

Resta evidente que a colisão dos referidos direitos fundamentais - em sentido estrito ou amplo - pode ser realizada com o sacrifício mínimo dos direitos contrapostos. Autorizado, pois, o legislador, em consideração à unidade da Constituição e a sua ordem de valores, a emitir regulação restritiva de um dos direitos envolvidos no conflito, que, contudo, jamais poderá se fazer de maneira absoluta.

Dessa forma, assentada a constitucionalidade em tese da internação psiquiátrica involuntária, cumpre anotar que tal modalidade de tratamento é forma de restrição do direito à liberdade e como tal deve ser cercada de cuidados para que sejam evitados excessos contra os pacientes.

A própria Lei 10.216/2001 (Art. $4^{\circ}$ ) determina a aludida internação como modalidade extraordinária, somente admissível quando os recursos extra-hospitalares se mostrarem insuficientes.

\section{O DEVIDO PROCESSO LEGAL DE INTERNAÇÃO PSIQUIÁTRICA INVOLUNTÁRIA NO DIREITO BRASILEIRO}

Infelizmente no Brasil, na inexistência de uma rede extra-hospitalar ampla e eficiente, o hospital psiquiátrico passa a ser a "porta de entrada" do sistema de saúde mental do país, e a internação um dos recursos preferencialmente utilizados.

Em verdade, a internação psiquiátrica somente deveria acontecer em hospitais gerais que possuem vocação assistencial, e não do tipo prisional ou asilar. A boa experiência da internação psiquiátrica nos ambientes aludidos é muito antiga (1902, no Albany Medical Center, em Nova lorque) e calha perfeitamente com o princípio da dignidade da pessoa humana (Art. $1^{\circ}$, III da CF/88), matriz genética de todos os direitos fundamentais, pois "mostrou concretamente a médicos, pessoal técnico e administrativo a possibilidade de se tratarem eficazmente doentes mentais em hospitais gerais"13.

(12) NOVAIS, Jorge Reis. As restrições aos direitos fundamentais não expressamente autorizadas pela constituição. Coimbra: Coimbra Editora, 2003. p. 449-450.

(13) BOTEGA, Neury Jr; DALGALARRONDO, Paulo. Saúde mental no hospital geral. São Paulo: Editora Hucitec, 1997. p. 15. 
Como demonstramos, resta evidente que a colisão de direitos fundamentais, que pode ser em sentido estrito ou amplo ${ }^{14}$, com o sacrifício mínimo dos direitos contrapostos, autoriza o legislador a emitir regulação restritiva de um dos direitos envolvidos no conflito, que jamais se poderá dar de maneira absoluta.

A Constituição brasileira, ao contrário da portuguesa, não prevê expressamente a possibilidade de restrição ao direito à liberdade por internação psiquiátrica, ficando para a Lei 10.216/2001 (Art. 6º parágrafo único, I, II e III) a tarefa de prever e classificar a internação em: 1) voluntária, aquela que se dá com o consentimento do usuário; 2) involuntária, aquela que se dá sem o consentimento do usuário e a pedido de terceiro; e 3) compulsória, aquela determinada pela justiça.

Os maiores problemas e excessos encontrados são com a internação involuntária, que se dá sem o consentimento do paciente, seja porque ele é contra a medida, seja porque está impossibilitado de decidir sobre ela. Note-se que a referida lei sequer tomou o cuidado de definir quem seriam esses "terceiros", que, evidentemente, não podem ser todos e quaisquer "terceiros", somente os legitimados para a interdição (Art. 1.177 do CPC), o representante legal e autoridades de saúde pública.

Essa modalidade excepcional de tratamento só deve ser admitida quando for a única forma de garantir a submissão ao tratamento do internado, e finda logo cessem os fundamentos que lhe derem causa.

A jurisprudência americana há muito definiu que a internação somente pode existir se tiver como fundamento um tratamento de saúde, jamais deve ser medida de simples restrição de liberdade.

Alfredo Jorge Kraut ${ }^{15}$ elenca princípios reitores e garantias na internação involuntária:

1) deve existir uma enfermidade mental verificada como passível de internação;

2) deve existir possibilidade de danos para si ou para terceiros;

3) o tratamento psiquiátrico prescrito deve considerar imprescindível a internação, por não existirem alternativas terapêuticas mais eficazes e menos restritivas do direito de liberdade;

(14) Segundo MENDES, Gilmar Ferreira. In: Colisão de direitos fundamentais na jurisprudência do Supremo Tribunal federal. Repertório IOB de Jurisprudência. São Paulo: IOB, 1/18145, mar., 2003. p. 185: "A doutrina cogita de colisão de direitos em sentido estrito ou em sentido amplo. As colisões em sentido estrito referem-se apenas àqueles conflitos entre direitos fundamentais. As colisões em sentido amplo envolvem os direitos fundamentais e outros princípios ou valores que tenham por escopo a proteção de interesses da comunidade".

(15) KRAUT, Alfredo Jorge. Los derechos de los pacientes. Buenos Aires: Abeledo-Perrot, 2000. p. 545. 
4) existência de um decreto judicial de internação, devidamente fundamentado, emitido com todas as garantias substanciais e procedimentais;

5) o término da internação não implica o fim do tratamento, que pode continuar na condição de voluntário;

6) direito a habeas corpus, de modo que o internado possa recorrer ao órgão judicial para que em um prazo breve se pronuncie pela legalidade de sua privação de liberdade;

7) direito a reparação dos danos sofridos e

8) a reclusão involuntária não deve se constituir, per se, um motivo suficiente para restringir a capacidade legal.

No Brasil, sob o regime da Lei $n^{\circ} 10.216 / 2001$, não há previsão de um procedimento de internação psiquiátrica que passe regularmente sob os auspícios do Poder Judiciário, sendo certo, entretanto, que o princípio constitucional do amplo acesso à jurisdição ${ }^{16}$ assegura a qualquer pessoa a possibilidade de, a todo momento, questionar judicialmente a referida internação.

É evidente e perigosa a falha da legislação brasileira nesse ponto, ao permitir a internação psiquiátrica involuntária sem a autorização (anterior ou posterior - convalidação do internamento de urgência) de um magistrado. Esse risco, o sistema constitucional de proteção à pessoa portadora de transtorno mental dos Estados Unidos, Argentina, África do Sul, Portugal, Espanha, entre outros países, expressamente eliminou, não por mera desconfiança na comunidade técnica, ou evidente esgotamento do modelo hospitalocêntrico, mas, sobretudo, para dar eficácia urgente ao entendimento sólido e sedimentado na contemporânea teoria dos direitos fundamentais: o portador de transtorno mental possui exatamente a mesma dignidade que qualquer outro ser humano física e mentalmente capaz ${ }^{17}$.

Lembre-se que a internação compulsória é aquela determinada pelo juiz competente (Art. $9^{\circ}$ da Lei $n^{\circ} 10.216 / 2001$ ), não se confundindo com a internação involuntária, que é a aquela que se dá sem consentimento do paciente, embora que seja certo não fazerem sentido internações compulsórias com consentimento.

A internação psiquiátrica involuntária (ou mesmo a compulsória) exige o chamado "devido processo legal de internação", que deverá ser obedecido como forma de garantia ao direito de liberdade da pessoa portadora de transtorno mental.

Como no Brasil não há previsão legal estipulando que toda internação passe regularmente pelo judiciário, espera-se que seja instituído, pelo menos, um corpo de revisão, encarregado de periodicamente rever todas as internações involuntárias.

(16) Constituição Federal da República Federativa do Brasil, Art. 5o., XXXV: "a lei não excluíra da apreciação do Poder Judiciário lesão ou ameaça a direito".

(17) SARLET, Ingo Wolfgang. Dignidade da Pessoa Humana e Direitos Fundamentais, $2^{\mathrm{a}}$ ed, Porto Alegre: Livraria do Advogado, 2002. p. 45. 
O devido processo legal de internação brasileiro, segundo a Lei 10.216/2001, exige que o procedimento se realize: a) mediante laudo médico circunstanciado (Art. $6^{\circ}$ ); b) mediante consentimento informado - do paciente ou de seu representante legal - escrito; c) autorização de médico devidamente cadastrado no Conselho Regional de Medicina do Estado onde se localize o estabelecimento; e d) comunicação, pelo responsável técnico do estabelecimento, no prazo de 72 horas, ao Ministério Público tanto da internação quanto da alta do paciente.

É claro que essa comunicação compulsória ao Ministério Público em casos de internação involuntária, e na respectiva alta, se faz para que possa o MP fiscalizar os estabelecimentos psiquiátricos, a fim de impedir excessos violadores dos direitos fundamentais dos pacientes.

Sobre a atuação do Ministério Público no âmbito da saúde, registram Maria Célia Delduque e Mariana Siqueira de Carvalho Oliveira:

no âmbito da saúde, um notável movimento vem se afigurando, tendo o Ministério Público como seu principal protagonista. Corajosos membros do MP, comprometidos com a saúde, começam a romper com alguns paradigmas existentes na instituição e criam agentes de contatos rotineiros com os atores e usuários do Sistema Único de Saúde. Descerram as portas da promotoria e se estabelecem como verdadeiros articuladores políticos, promovendo uma real participação da sociedade na busca de alternativas de atenção à saúde, identificam demandas, acompanham e controlam o uso de recursos públicos e responsabilizam o estado por sua má atuação ou inação em relação à saúde ${ }^{18}$.

A não observância desse devido processo legal enseja a impetração de habeas corpus, garantia constitucional do direito à liberdade. Esta garantia não implica necessariamente no envio do paciente às ruas, pois se admite a impetração da referida ordem constitucional para recolocá-lo em ambiente verdadeiramente terapêutico, que respeite a sua dignidade e possa ministrar-lhe tratamento adequado e eficaz.

\section{O HABEAS CORPUS}

O habeas corpus é uma ação constitucional voltada para a libertação do "paciente" (utiliza-se esse termo técnico mesmo fora de um contexto de saúde) que esteja sofrendo lesão ou ameaça ao seu direito fundamental à liberdade de ir e vir.

Diz o Art. 5, LXVIII, da Constituição Federal: "conceder-se-á habeas corpus sempre que alguém sofrer ou se achar ameaçado de sofrer violência ou coação em sua liberdade de locomoção, por ilegalidade ou abuso de poder".

(18) DELDUQUE, Maria Célia; OLIVEIRA, Mariana Siqueira de Carvalho. O papel do ministério público no campo do direito e saúde. In: MINISTÉRIO DA SAÚDE; FUNDAÇÃO OSWALDO CRUZ. Questões atuais de direito sanitário. Brasília: Editora MS, 2006. p. 14. 
Evidentemente que essa ação constitucional também pode ser ajuizada quando o estabelecimento hospitalar não assegurar os direitos da pessoa portadora de transtorno mental, previstos na Constituição da República e no parágrafo único do Art. $2^{\circ}$ da Lei 10.216/2001.

Registre-se que o paciente mantém, mesmo internado involuntariamente, o seu direito à liberdade de religião e consciência, possuindo direito à comunicação, à proteção de seu patrimônio, à livre expressão e ao direito de ação, inclusive direito a voto, não estando interditado (Art. 15, II, da CF/88), nos termos da facultatividade instituída pela Resolução $n^{\circ} 21.920$ do Tribunal Superior Eleitoral - TSE.

\section{Esclarece Luís Roberto Barroso que:}

o habeas corpus pode ser impetrado por qualquer pessoa física ou jurídica, e também pelo Ministério Público (...), em favor logicamente de pessoa física, única capaz de ver tolhida sua liberdade de locomoção. Sequer é exigida capacidade postulatória do impetrante. E, mesmo que ninguém o impetre, poderão os juízes e tribunais competentes expedir, de ofício, ordem de habeas corpus ${ }^{19}$.

Embora tenha existido alguma controvérsia sobre o assunto, atualmente doutrina e jurisprudência admitem a utilização de habeas corpus contra atos de particular (diretores de clínicas ou hospitais psiquiátricos, por exemplo).

\section{Como explica Heráclito Antônio Mossin, o habeas corpus}

não se projeta exclusivamente no campo penal ou processual, porquanto é ele cabível também na área extra persecutio criminis, visando tutelar o direito de liberdade corpórea do indivíduo quando estiver sendo lesada ou ameaçada de sê-lo, abusivamente por qualquer pessoa, aqui se incluindo o particular ${ }^{20}$.

No mesmo sentido, se pronuncia Fernando Capez, para quem "prevalece o entendimento de que pode ser impetrado habeas corpus contra ato de particular, pois a Constituição fala não só em coação por abuso de poder, mas também por ilegalidade. 'Por exemplo: filho que interna pais em clínicas psiquiátricas, para deles se ver livre'"21.

O Superior Tribunal de Justiça também admite impetração de HC contra internação psiquiátrica involuntária irregular:

\section{Ementa}

Habeas Corpus. Internação involuntária em clínica psiquiátrica. Ato de particular. Ausência de provas e/ou indícios de perturbação mental. Constrangimento ilegal delineado. Binômio poder-dever familiar. Dever de cuidado e proteção. Limites. Extinção do poder familiar. Filha maior e civilmente capaz. Direitos de personalidade afetados.

(19) BARROSO, Luís Roberto. O direito constitucional e a efetividade de suas normas: limites e possibilidades da constituição brasileira, $7^{a}$ ed. Rio de Janeiro: Renovar, 2003. p. 184-185.

(20) MOSSIN, Heráclito Antônio. Habeas Corpus. $7^{a}$ ed. Barueri: Manole, 2005. p. 77.

(21) CAPEZ, Fernando. Curso de processo penal. $12^{a}$ ed. São Paulo: Saraiva, 2005. p. 493. 
- É incabível a internação forçada de pessoa maior e capaz sem que haja justificativa proporcional e razoável para a constrição da paciente.

- Ainda que se reconheça o legítimo dever de cuidado e proteção dos pais em relação aos filhos, a internação compulsória de filha maior e capaz, em clínica para tratamento psiquiátrico, sem que haja efetivamente diagnóstico nesse sentido, configura constrangimento ilegal.

Ordem concedida ${ }^{22}$.

Assim, além das ações de indenização por danos morais e materiais causados pela internação psiquiátrica involuntária irregular, é possível o manejo de habeas corpus para assegurar o pleno exercício do direito fundamental de ir e vir da pessoa portadora de transtorno mental que tenha sido internada sem consentimento, em desconformidade com o devido processo legal delineado, ou que esteja sofrendo violação a seus direitos fundamentais constitucionalmente garantidos.

\section{CONSIDERAÇÕES FINAIS}

Talvez o maior erro político do movimento social em saúde mental, nele envolvidos os profissionais de saúde mental, organizações, os pacientes e familiares, tenha sido não conseguir enxergar na Constituição Federal de 1988 o marco jurídico potente e eficiente para a efetivação de todas as mudanças necessárias para o setor. É urgente uma "saúde mental constitucional"; são cerca de 40 anos de atraso doutrinário e jurisprudencial com relação a inúmeros países.

A comunidade jurídica também tem participação nessa cegueira normativa, em que ainda hoje a saúde mental se mostra envolvida, pois todos, parece, até o momento, acreditam que a Lei Federal $n^{\circ} 10.216 / 2001$ é o marco jurídico da saúde mental brasileira, ignorando a forma normativa da Constituição da República Federativa do Brasil e a abertura principiológica que ela produz a cada novo dia, permitindo ao intérprete efetivar como nunca a proteção e a realização dos direitos fundamentais das pessoas portadoras de transtornos mentais.

É, pois, da Constituição que deriva o devido processo legal de internação psiquiátrica involuntária e suas fundamentais consequências e garantias. Realidade constitucional fundante ainda ignorada pela magistratura, advocacia, Ministério Público, profissionais da área e pelo movimento social em saúde mental.

Mesmo ainda em potência, viva a Constituição! O tempo da saúde mental ainda está por vir. O tempo da saúde mental constitucional.

(22) Superior Tribunal de Justiça, HC 35301 / RJ, T3, Rel. Min. Nancy Andrighi, DJ de 13/09/2004. 


\section{REFERÊNCIAS}

ANDRADE, José Carlos Vieira de. O internamento compulsivo de portadores de anomalia psíquica na perspectiva dos direito fundamentais. In: CARVALHO, Álvaro de. et al. (Orgs.). A lei de saúde mental e o internamento compulsivo. Coimbra: Coimbra Editora, 2000.

BARRETO, Irineu Cabral Barreto. A Convenção Européia dos Direitos do Homem Anotada. $2^{a}$ Ed. Coimbra: Coimbra Editora, 1999.

BARROSO, Luís Roberto. O direito constitucional e a efetividade de suas normas: limites e possibilidades da constituição brasileira. $7^{\text {a }}$ Ed. Rio de Janeiro: Renovar, 2003.

BONAVIDES, Paulo. Curso de direito constitucional. $13^{\mathrm{a}}$ Ed. São Paulo: Malheiros, 2003.

CAPEZ, Fernando. Curso de processo penal. $12^{a}$ Ed. São Paulo: Saraiva, 2005.

BOTEGA, Neury Jr ; DALGALARRONDO, Paulo. Saúde mental no hospital geral. São Paulo: Editora Hucitec, 1997.

DELDUQUE, Maria Célia; OLIVEIRA, Mariana Siqueira de Carvalho. O papel do ministério público no campo do direito e saúde. In: MINISTÉRIO DA SAÚDE; FUNDAÇÃO OSWALDO CRUZ. Questões atuais de direito sanitário. Brasília: Editora MS, 2006.

MENDES, Gilmar Ferreira. Os direitos individuais e suas limitações: breves reflexões. In: MENDES, Gilmar Ferreira. Hermenêutica constitucional e direitos fundamentais. Brasília: Brasília Jurídica, 2002,

Repertório IOB de Jurisprudência. São Paulo: IOB, 1/18145, mar., 2003.

MOSSIN, Heráclito Antônio. Habeas Corpus. $7^{\text {a }}$ Ed. Barueri: Manole, 2005.

NOVAIS, Jorge Reis. As restrições aos direitos fundamentais não expressamente autorizadas pela constituição. Coimbra: Coimbra Editora, 2003.

KRAUT, Alfredo Jorge. Los derechos de los pacientes. Buenos Aires: AbeledoPerrot, 2000.

PORTANOVA, Rui. Princípio do processo civil. $4^{a}$ Ed. Porto Alegre: Livraria do Advogado, 2001.

SARLET, Ingo Wolfgang. Dignidade da Pessoa Humana e Direitos Fundamentais. $2^{\mathrm{a}}$ Ed. Porto Alegre: Livraria do Advogado, 2002.

STEINMETZ, Wilson. A vinculação dos particulares a direitos fundamentais. São Paulo: Malheiros, 2004. 